\title{
El estado de la virtud. Sobre la noción de tolerancia en el liberalismo político de John Rawls
}

\author{
SEBASTIÁN ESCÁMEZ NAVAS * \\ Universidad de Málaga
}

RESUMEN. En este trabajo ** se aborda la noción de tolerancia en el liberalismo político de John Rawls en lo que toca a la parte más general de esta teoría, que es la referida a una sociedad política, y no a su extensión a las relaciones internacionales ***. El esclarecimiento de esta noción ha de hacer frente a la polisemia que afecta al concepto de tolerancia, a la que Rawls no es ajeno. De esta manera, por un lado, se hallará que Rawls cuenta con la virtud de la tolerancia de aquellas personas para quienes se elige la concepción política de la justicia. La expectativa de que los ciudadanos manifiesten tal virtud se expresa en obligaciones de éstos - como la de ser razonables, reconocer las cargas del juicio o cumplir con el deber de civilidad - , las cuales son examinadas someramente. Pero también, en
ABSTRACT. This paper approaches the idea of toleration in John Rawls' political liberalism. In particular, it is the general theory what is considered, not the application of it to international relations. Enlightening that idea requires to discuss the different meanings of «toleration» as can be distinguish in Rawls' liberalism: On the one hand, Rawls relies that those people for whom the political conception of justice is chosen will have the virtue of toleration. This bargaining for that virtue carries citizens' duties, as the duty to be reasonable, recognizing the burdens of reason or the duty of civility; obligations that will be briefly examined. On the other hand, toleration appears as a principle of legitimacy in Rawls' political liberalism: as a principle that gives us reasons

* Sebastián Escámez Navas es Profesor de Ciencia Política y de la Administración en la Universidad de Málaga. Dedicó su tesis doctoral a los modos contemporáneos en los que se presenta la idea liberal de tolerancia y sobre este tema versan sus publicaciones de los últimos años: acerca de la evolución del concepto de tolerancia, la relación entre tolerancia y derecho, la teoría de la tolerancia de Michael Walzer y Richard Rorty o el examen de la autocomprensión de las sociedades democráticas como «sociedades tolerantes». También ha escrito sobre teoría de la democracia, el componente ideológico de la traducción y el pensamiento pluralista. Este trabajo se enmarca en el proyecto BS-2003/3746.

** Versiones anteriores de este artículo fueron presentadas en el XII Congreso de la Asociación Española de Ética y Filosofía Política (Castellón, 2003) y en el VI Congreso de la Asociación de Ciencia Política y de la Administración (Barcelona, 2003). Agradezco los comentarios que en estos foros se me hicieron, particularmente los de Rafael del Águila y Daniel Gamper. Igualmente el trabajo se ha beneficiado de una exhaustiva crítica de forma y de fondo debida a la generosidad de Rafael Caparrós. Fernando Vallespín fue quien hace algunos años me sugirió el tema del artículo y con ello toda una línea de investigación.

*** Esta restricción obedece a razones de espacio, no a que la noción de tolerancia en el contexto del derecho de gentes rawlsiano no sea importante. 
el liberalismo político, la tolerancia aparece como un principio de legitimidad; como un principio discriminador de las razones susceptibles de justificar los fines y la organización de la estructura básica de la sociedad. Virtud y principio mantienen una relación de complementariedad, pero también cierta tensión. $Y$ es que, dada la jerarquía de valores presupuesta por la virtud de la tolerancia, resulta problemático considerar tal virtud como un valor político básico allí donde el principio de tolerancia rige sobre los fundamentos del orden sociopolítico. which justify the ends and organization of the basic structure of society. Then, virtue and principle of toleration are complementary but also maintain strained relations. In view of the hierarchy of values that virtue of toleration presupposes, it does not fit appraising that virtue as a basic political one where the principle of toleration rules the foundations of socio-political order.

\section{LA VIRTUD Y EL PRINCIPIO DE TOLERANCIA EN EL LIBERALISMO POLÍTICO}

\section{1. La tolerancia como virtud en el liberalismo político}

Que la tolerancia es un concepto básico de El liberalismo político es una conclusión que se deriva de la misma lectura de la introducción al libro $(P L, \text { pp. xiv-xxxiv [9-29] })^{1}$. La centralidad de este concepto no se restringe, sin embargo, a la obra citada. Afecta a toda la visión normativa que el referido libro representa por excelencia, pero que incluye trabajos anteriores y posteriores a aquél: todo el pensamiento desarrollado por Rawls a partir de «El constructivismo kantiano en la teoría moral» y hasta su muerte, un pensamiento que el propio autor definió como liberalismo político ${ }^{2}$.

El destacado lugar de la tolerancia en la obra del segundo Rawls, como también se conoce su liberalismo político, coincide con la creciente invocación a la tolerancia que se viene dando en las sociedades democráticas desde hace algún tiempo, y que debe explicarse por motivos diversos: principalmente por un incremento del contacto entre culturas como consecuencia del desarrollo de las comunicaciones y de los flujos migratorios, pero también por las reacciones tradicionalistas y nacionalistas ante la pujanza adquirida

'Dada la frecuencia con que es citado, se ha optado por abreviar El liberalismo político (Rawls, 1993) por PL. Siguiendo una práctica frecuente, cuando se citan páginas y no parágrafos de esta obra, las referencias a la versión castellana aparecen entre corchetes y en cursiva. También se citan de esta forma las versiones castellanas de Teoría de la Justicia (Rawls, 1971), «Kantian Constructivism in Moral Theory» (Rawls, 1980), «Social Unity and Primary Goods» (Rawls, 1982) y «The Idea of Public Reason Revisited» (Rawls, 1997). Cuando las referencias a citar sean numerosas, se incluirán a pie de página, para no entorpecer la lectura.

${ }^{2}$ Rawls (1987, pp. 446 ss.); $P L$, pp. xiv-xx, 10-15 y 43 ss. [10-15, 40-45; 73 ss.]; Rawls $(1997,2.1)$. 
por los procesos de integración económica y cultural de carácter regional y global; todo lo cual conlleva la irrupción de movimientos políticos que cuestionan el modelo de relaciones que con ciertos grupos diferenciados mantiene un Estado liberal supuestamente «ciego a las diferencias». No obstante, el sentido de la tolerancia en el liberalismo de Rawls no se deja interpretar simplemente a la luz de estas crecientes apelaciones a la tolerancia. Por dos razones:

La primera es que, al igual que ocurre con cualquier otra idea relevante en el pensamiento de un filósofo, el significado de la tolerancia en el liberalismo político de Rawls viene dado por el conjunto de su teoría. Por eso el estudio de tal significado equivale a revisar el liberalismo político rawlsiano y sus problemas desde el punto de vista del papel que desempeñan en ellos ideales y prácticas identificables con la tolerancia. Esta dependencia respecto de un marco normativo específico es por lo demás predicable del común de las prácticas y los valores sociales. La particularidad de la tolerancia es que, como quiera que ésta supone un dejar hacer algo que reprobamos o nos disgusta, resulta muy evidente la falta de sentido de tal omisión sin una justificación que predomine sobre las razones que motivan nuestro rechazo inicial.

La segunda razón que impide una lectura de la idea liberal-política de tolerancia contando sin más con las demandas comunes a ese valor tiene que ver con su polisemia. «Tolerancia» significa a día de hoy cosas distintas, algunas de ellas incluso contradictorias. No es raro que se reclame tolerancia con el sentido de «respeto por lo diferente» y también la hallamos referida a prácticamente todo el espectro de motivaciones y disposiciones ante las diferencias: la resignación, la aceptación estoica, la indiferencia, la curiosidad o el entusiasmo ${ }^{3}$.

Sin embargo, tanto la etimología como la historia de la tolerancia están asociadas con consentir algo que reprobamos o nos disgusta, y esta asociación no sólo es básica en el pensamiento conservador acerca de la articulación de las diferencias (véase, por ejemplo, Gray, 1995, cap. 3). También está presente en la comprensión de la tolerancia que predomina en las relaciones privadas, y en el reflejo de ésta que son las definiciones de los filósofos morales. Muy adecuado en este sentido me parece identificar la virtud moral o política de la tolerancia con una disposición a no intervenir contra ideas o prácticas que lesionan razonablemente nuestras convicciones. Por paradójico que resulte, hay que exigir que sea razonable la inicial reprobación que se supera con la tolerancia, pues de otro modo nos enfrentamos a la paradoja aún mayor de que cuantos más prejuicios tenga una persona, por caprichosos y detestables que éstos nos parezcan, más oportunidad tiene de

${ }^{3}$ Este modo tan amplio de entender la tolerancia lo preconiza entre otros Walzer (1998, pp. 13-21). 
ser considerada tolerante. $\mathrm{Y}$ es que, aunque de una jerarquía normativa se desprenda que existe una ganancia siempre que la intolerancia cede ante la tolerancia, este aprecio al hecho objetivo no se corresponde en todo caso con el reconocimiento de mérito moral. Así, desde el punto de vista de los valores públicos de una democracia liberal, la conducta pacífica de un racista visceral (por más que sea preferible a un comportamiento violento) no puede estimarse como una manifestación de la virtud de la tolerancia ${ }^{4}$. Como espero demostrar, este concepto de la tolerancia como virtud que aquí se propone aprehende en buena medida la idea rawlsiana de tolerancia, asociada al carácter razonable de los ciudadanos.

\section{2. La diversidad social potencialmente conflictiva que justifica la tolerancia}

Rawls (1987, p. 439) considera expresamente la tolerancia como una virtud muy importante, un gran bien público que constituye parte de ese capital político de la sociedad que hace posible un régimen constitucional. Tanto es así, que de la manifestación de esta virtud depende que una persona sea considerada miembro pleno de la sociedad, entendida, como postula Rawls, a la manera liberal; esto es, no como una comunidad de personas ligada por una tradición o modo de vida, sino como un sistema equitativo de cooperación $(P L, \mathrm{I}, \S 3.3 ; \mathrm{V}, \S 5.5 ; \mathrm{I}, \S 7)$. La razón de que la tolerancia resulte tan relevante tiene que ver con que un rasgo básico de las democracias liberales es la existencia en ellas de diversas doctrinas religiosas, filosóficas y morales y con que esta característica no constituye otra cosa que el resultado normal del desarrollo de la razón humana en el marco de instituciones libres. Este hecho del pluralismo cosmovisivo, el cual Rawls reconoce no haber tenido en cuenta lo suficiente en Una Teoría de la Justicia, determina que la cooperación a lo largo del tiempo sólo sea posible si las diferencias entre sus ideas y creencias no impiden la unión social ${ }^{5}$. Y al objeto de lograr tal cooperación parece bastante lógico que Rawls cuente con que los ciudadanos no conciban el poder político como un medio para intervenir contra ideas o prácticas que no se ajustan a sus respectivas convicciones particulares.

Para apreciar la importancia otorgada por Rawls a la virtud de la tolerancia, hay que tener en cuenta que, además de las referencias explícitas, la tolerancia aparece con frecuencia apelada de manera indirecta bajo el nombre de virtudes que la integran o en las que se concreta. Me refiero a virtudes como la razonabilidad o el deber de civilidad (de recurrir a la razón

\footnotetext{
${ }^{4}$ Horton (1996, pp. 30-32). Una postura distinta sostienen Garzón Valdés (1992, pp. 19-21) y Schmitt (1992, p. 77).

${ }^{5}$ Rawls (1985, p. 390; 1987, p. 425); PL, pp. xvi ss. [12 ss.] 3-4 [33-34], I, \$ 2.3; Rawls (1997, pp. 573-574 [155-156])
} 
pública en determinados casos o de mostrarse dispuestos a escuchar a los demás y evaluar ecuánimemente cuándo resultaría razonable acomodarnos a sus puntos de vista). El ámbito de estas manifestaciones virtuosas de la tolerancia coincide en todo caso con lo que algunos filósofos morales identifican como una (o dos) de las circunstancias de la tolerancia: la existencia de una diversidad social potencialmente conflictiva ${ }^{6}$.

Pero a Rawls no le preocupa cualquier fuente de diversidad. Cuando Rawls piensa en el pluralismo, lo hace acerca de una diversidad de doctrinas comprehensivas (esto es, que incorporan una visión global del mundo, la historia o la sociedad) sobre las cuales no puede esperarse un acuerdo razonado y libre de coacciones, según se desprendería de una larga experiencia histórica confirmada por «multitud de reflexiones plausibles» 7 . De hecho, a partir de su artículo «El constructivismo kantiano en la teoría moral», Rawls (1980, pp. 326-327 [158]) empieza a concebir las diferencias entre las concepciones del bien de la gente con arreglo al modelo de las discrepancias religiosas que, al radicar en la fe, no pueden superarse mediante el diálogo racional. Y paralelamente a cómo las divisiones sociales de base religiosa proveen a Rawls del modelo conceptual e histórico para inteligir las divergencias de convicción irreductibles, también la forma en que históricamente se han articulado tales divisiones le ofrece la respuesta adecuada al problema del pluralismo (Mendus, 1998, p. 4). De ahí que la institución de la tolerancia religiosa como solución a las guerras de religión subsiguientes a la Reforma sea un referente continuo en sus reflexiones sobre cómo afrontar el hecho del pluralismo a partir de «La justicia como equidad: política, no metafísica» ${ }^{8}$. Rawls (1985, p. 412; PL, p. xxiv [20J) 1lega, de hecho, a identificar tal institución como el origen histórico «del liberalismo político (y del liberalismo en general)».

En cuanto a las «reflexiones plausibles» en razón a las cuales no podría esperarse un acuerdo razonado y libre de coacciones acerca del contenido comprehensivo de las doctrinas religiosas o filosóficas, éstas vendrían dadas, para Rawls, por las cargas del juicio o cargas de la razón (burdens of reason, burdens of judgment). Con estas denominaciones de resonancias kuhnianas Rawls alude a un elenco de factores que explicarían por qué las personas, aun estando completamente facultadas para conocer y actuar según lo requerido en una sociedad democrática, pueden no ponerse de acuerdo sobre la verdad o corrección de concepciones del mundo distintas a las suyas. Factores que dificultan la apreciación de la evidencia y la ponderación de las razones, como puedan ser la imprecisión de los conceptos, la complejidad de la evidencia empírica, la existencia de razones de peso a ambos lados de una disputa, el condicionamiento de las experiencias perso-

\footnotetext{
6 Véanse por todos Mendus (1989, p. 8) y Garzón Valdés (1992, p. 16).

7 Rawls (1980, p. 329 [160]; 1987, p. 425); PL, pp. xvi, 54 ss. [12, 85 ss.].

${ }^{8}$ Rawls (1985, pp. 390, 395; 1987, pp. 424, 433); $P L$, pp. xxii-xxviii y 159 ss. [17-24, 191 ss.].
} 
nales o la incompatibilidad de ciertos valores dentro de un mismo espacio social (PL, I., § 6.1; II, § 2.2-3).

La consecuencia de admitir la existencia de las cargas del juicio es que, con ello, se acepta que no puede establecerse la verdad o falsedad universal de un número indeterminado de concepciones del mundo existentes. Tal aceptación no supone ninguna postura escéptica al respecto, ni tampoco negar el valor epistemológico y moral de las concepciones globales de la existencia: estas concepciones permiten satisfacer una necesidad fundamental, cual es la de ofrecer un patrón de lo que supone una vida lograda y «auténtica» frente a los autoengaños y los síntomas de un modo de vida forzado o alienado (Habermas, 1998c, p. 56). Lo que sí conlleva el reconocimiento de las cargas del juicio es asumir que la verdad o corrección de las concepciones existenciales es relativa a su aceptación por las comunidades de valor que las comparten. $O$ en otras palabras: quien da por buena la existencia de las cargas del juicio, entiende que cualquier persona puede pensar legítimamente que su propia concepción existencial es tan verdadera o correcta como cualquier otra (Mendus, 1998, pp. 12 ss.).

La «disposición a admitir las cargas del juicio» forma parte de las facultades morales que, según Rawls, una persona debe tener para ingresar como un igual en el mundo público de los demás; o lo que es lo mismo: forma parte de lo que significa ser razonable (constituyendo su «segundo aspecto básico»). Esto supone que el pluralismo que caracteriza las sociedades democráticas modernas según el liberalismo político es un pluralismo razonable. Lo cual tiene dos consecuencias para la idea liberal-política de tolerancia: la primera, que puede contarse con una disposición general al respeto de la diversidad de formas de vida y que este respeto traza una frontera entre las formas de vida aceptables dentro de una sociedad democrática y las que no lo son. La segunda consecuencia es que el pluralismo que cuenta a la hora de concebir los principios fundamentales del orden social es el surgido de los desacuerdos razonables, esto es, de esas discrepancias no fundadas en la maldad o el error que una persona razonable es capaz de reconocer como causa de las diferencias entre las cosmovisiones compatibles con un orden democrático (véase $L P$, II, $\S 1.1 ;$ II, $\S 2.1-2$ ). Por ello, las objeciones a la validez de una doctrina que tengan que ver con alguna de sus pretensiones comprehensivas de verdad o corrección deberán ser apreciadas como objeciones razonables. La presencia de este tipo de objeciones constituye una circunstancia decisiva del valor moral de la tolerancia, ya señalada: que el rechazo inicial sentido hacia una creencia o práctica no sea arbitrario desde la óptica normativa relevante.

Para el liberalismo político, las mismas circunstancias que justifican el carácter razonable de las discrepancias entre doctrinas comprehensivas justifican, igualmente, lo que podrían denominarse como deberes de tolerancia. Así, resultará obligado reconocer el rango moral de aquellas cosmovisiones 
o formas de vida de las que nos separan desacuerdos razonables, a pesar de la disconformidad con ellas. Del mismo modo, no cabrá pretender que los demás acepten una justificación acerca de cuestiones políticas fundamentales que implique aceptar una concepción global de la existencia cuando razonablemente se pueda no estar conforme con tal concepción. De ahí que la apelación a la razón pública en el foro público siempre que se discutan tales cuestiones se erija como un deber de civilidad. Debemos tolerar, pues, que nuestros puntos de vista comprehensivos no sirvan de referencia obligada para la resolución de cuestiones políticas fundamentales, a pesar de que públicamente ni se niegue su valor epistemológico ni se niegue su valor moral. Y también la civilidad obliga a escuchar a los demás, mostrarse equitativo en decidir cuándo acomodarse a sus posiciones y buscar puntos de convergencia con éstas ${ }^{9}$.

\subsection{Moral y prudencia como razones de una virtud}

Conforme a lo expuesto, parece claro que, por mucho que reconozca que el liberalismo tiene sus raíces en los diversos argumentos en defensa de la tolerancia religiosa desarrollados en los siglos XVI y XVII, a Rawls no le interesa cualquier forma de tolerancia ni cualquier justificación de ésta. Para el liberalismo político de Rawls, la superación de las dificultades derivadas de la diversidad de creencias (Rawls no piensa en la diversidad de prácticas más que como derivada de la de creencias) debe venir motivada por lo que, por oposición a las razones prudenciales, podría definirse como razones morales. Esto es determinante del carácter moral que tienen tanto la virtud de la tolerancia en el liberalismo político como las obligaciones a ella asociadas: el deber de justificar nuestros puntos de vista apelando a valores políticos susceptibles de ser compartidos por todos en vez de a concepciones particulares y los deberes análogos relativos a la escucha y la acomodación a los puntos de vista de los demás, así como a repudiar aquellos cargos públicos que no actúen ateniéndose a los referidos valores políticos tanto en el ámbito interno como en las relaciones internacionales $(P L, \mathrm{VI}, \S 2.2$; Rawls, 1997, p. 577 [160]).

Lo anterior no significa que Rawls niegue la ventaja que frente a una situación de conflicto representa un régimen de tolerancia basado en compromisos. Y ello aunque este régimen se halle sometido al albur de las circunstancias y del equilibrio de fuerzas, al depender de intereses ya configurados en vez de incidir en la configuración de tales intereses. Pero frente a, por ejemplo, John Gray (2001, cap. 1), el fallecido profesor de Harvard confía en la posibilidad de que la tolerancia se sustente en valores compartidos.

\footnotetext{
${ }^{9}$ Sobre las obligaciones correspondientes al deber de civilidad, véase infra parágrafos 2.2 . y 2.3 .
} 
Por eso cuando piensa en un modus vivendi lo concibe como un paso en la configuración de un régimen de tolerancia que sea más estable por radicar su aceptación en convicciones profundas al tiempo que susceptibles de motivar un consenso (Rawls, 1985, pp. 444-446; $P L$, IV, § 3; IV, § 5).

No obstante - como, por lo demás, es norma en prácticamente todas las teorías de la tolerancia (Del Águila, 2003, p. 381) -, también en el liberalismo político la determinación concreta de los límites de la tolerancia remite al cálculo prudencial. De modo general para el liberalismo político estos límites vienen dados por la concepción de la justicia, concretamente por el respeto a los derechos reconocidos por los principios de la justicia y porque no se ponga en riesgo el sistema de libertades para la generalidad de los ciudadanos. También es norma general que la interpretación de estos supuestos deba hacerse restrictivamente, en el sentido de que no resultan admisibles más limitaciones a la libertad que las necesarias para procurar que todos los ciudadanos disfruten de las mismas libertades. A tal efecto, hay criterios que pueden resultar útiles, como el de que una libertad no debe recortarse si no es para prevenir el daño de su pérdida o el de la pérdida de otras libertades básicas y no exista otra manera de prevenir tales daños ( $P L$ [232, 378-379, 394 I). Pero el establecimiento de cuándo se dan las circunstancias aludidas es algo que inevitablemente conlleva un cálculo de consecuencias políticas: una ponderación de los daños que acarrea tolerar frente a dejar de hacerlo.

Igualmente cabe entender que la tolerancia prudencial informada por los principios normativos constituye un recurso ordinario de la política en una sociedad democrática, según el liberalismo político. Un ejemplo de ello nos lo ofrece la tolerancia que en condiciones normales se debe a los mensajes que instan a la subversión, según Rawls. En línea con algunas justificaciones funcionales de la tolerancia que hallamos en época medieval -particularmente con la de Marsilio de Padua (Nederman, 1996, pp. 28-30)—, Rawls entiende que esta tolerancia beneficia a la buena marcha del régimen democrático. La razón es que con tal tolerancia de las manifestaciones subversivas las autoridades ganan la ocasión de conocer las demandas insatisfechas de los ciudadanos y el sistema político tiene ocasión de reaccionar a tiempo.

\subsection{El problema político que exige tolerancia}

Otra característica de la virtud rawlsiana de la tolerancia es - como a buen seguro conoce el lector y, por lo demás, ha sido avanzado - su referencia a la solución de problemas políticos, por oposición a los morales. Más concretamente, la tolerancia en el segundo Rawls ( $P L$, pp. xvii-xviii [13J) se orienta primordialmente a solventar un problema político: «¿cómo es posible que pueda persistir en el tiempo una sociedad estable y justa de ciudadanos libres e iguales que andan divididos por doctrinas religiosas, filosóficas y 
morales razonables pero incompatibles?». Este problema surge en el contexto de una reflexión que Rawls venía desarrollando acerca de los principios de justicia que deberían regir la estructura básica de una sociedad democrática moderna ${ }^{10}$. En otras palabras: la tolerancia en el liberalismo político de Rawls viene a completar la justificación de los principios que deberían regular la organización y los fines de las instituciones sociales más importantes - como la constitución política, las formas legales de propiedad, la organización de la economía o de la familia-, en la medida en que éstas asignan derechos y deberes y configuran la distribución de las ventajas surgidas de la cooperación social ${ }^{11}$.

Rawls se da cuenta de que el modo en que fundamentó tales principios en su Teoría de la Justicia podía dar lugar a que se interpretase que estaban basados en tesis psicológicas, sociológicas, históricas, epistemológicas o metafísicas controvertidas. Y considerando el sinsentido de esperar que estas discrepancias desaparezcan en las condiciones sociohistóricas de las democracias modernas, concluye que la concepción pública de la justicia en estos regímenes debería ser, en la medida de lo posible, independiente de doctrinas filosóficas o religiosas.

La elusión de estas cuestiones filosóficas o morales no se defiende porque carezcan de la suficiente relevancia o interés. Todo lo contrario: los desacuerdos referidos implican entre otras cosas diferentes concepciones acerca de lo que hace posible alcanzar la vida eterna, tal es la naturaleza salvífica de algunas de las religiones desarrolladas en el medievo y todavía establecidas en las sociedades modernas. Sin embargo, según Rawls, la Historia nos muestra que el pluralismo filosófico y religioso persiste allí donde no se ve reprimido, esto es, allí donde el marco jurídico-político permite a la razón humana desplegarse libremente. Por otra parte, como se ha expuesto, las cargas del juicio nos hablan del error que supondría considerar que las diferentes concepciones del mundo tan sólo son el producto contingente de la falta de conocimientos o de un razonamiento defectuoso. Habida cuenta

${ }^{10}$ Rawls (1971, p. 7 [23]; 1980, p. 305 [139]). En estas obras se define la empresa intelectual de Rawls.

"Sobre el concepto de estructura básica, véase Rawls (1982, p. 362 [189-190]; PL, pp. 33-41 y 293). Según la última formulación de los principios de la justicia ofrecida por Rawls (2002, p. 73), éstos rezan así: «a) cada persona tiene el mismo derecho irrevocable a un esquema plenamente adecuado de libertades básicas iguales que sea compatible con un esquema similar de libertades para todos, y $b$ ) las desigualdades sociales y económicas tienen que satisfacer dos condiciones: en primer lugar, tienen que estar vinculadas a cargos y posiciones abiertos a todos en condiciones de igualdad equitativa de oportunidades, $y$, en segundo lugar, las desigualdades deben redundar en un mayor beneficio de los miembros menos aventajados de la sociedad (el principio de diferencia)». La aplicación de estos principios está sujeta a la siguiente regla de prioridad, que sirve para dirimir casos difíciles: la aplicación del segundo principio está sujeta a que el primero se vea satisfecho y lo mismo ocurre con la segunda parte del segundo principio (el principio de diferencia) respecto a la primera. Para una exposición breve y actualizada del sentido de estos principios, véase ibid., $\$ 13$ 
de todo ello, Rawls concluye que «la filosofía como búsqueda de la verdad sobre un orden moral o metafísico no podría ofrecer una base operativa y compartida para una concepción política de la justicia en una sociedad democrática». Ninguna justificación de la organización y los fines públicos basada en doctrinas comprehensivas sería capaz de atraerse un consenso racionalmente motivado, por lo que un poder estatal fundado en tales consideraciones sería por naturaleza oligocrático (Rawls, 1985, pp. 388-390, 394-395).

\section{5. La tolerancia, también principio de legitimidad}

La alternativa a esta respuesta oligocrática pasa, según Rawls, por la tolerancia. Por una virtuosa disposición a la tolerancia de los ciudadanos, desde luego: con esta virtud cuenta Rawls como materia prima de su liberalismo político, ya que es parte del capital político de una sociedad democrática que hace posible en ella un régimen constitucional democrático. Pero Rawls no hace descansar todo el orden político en un agregado espontáneo de virtudes. Éstas aparecen, como se ha dicho, dentro de una reflexión sobre los principios que deberían regular las instituciones sociales y la distribución de derechos, deberes y ventajas surgidas de la cooperación social.

Según Rawls, la disposición a no intervenir contra creencias y prácticas que lesionan las propias convicciones antecede al establecimiento de los principios del orden social ${ }^{12}$. Sin embargo, la justificación y el contenido de la virtud de la tolerancia están ligados a la concepción política de la justicia que contiene los principios regulativos de la estructura básica de la sociedad, al igual que las pautas para su interpretación. Lo aleccionador de las prácticas de tolerancia con que se puso fin a las guerras y persecuciones derivadas de la Reforma, lo que motiva reiteradas alusiones a este episodio, no se resume, para Rawls, en la evidencia de lo bueno que resulta sobreponerse a la inclinación de imponer la propia voluntad de cualquier forma. A pesar de que coincida con Judith Shklar (1984) en identificar el origen del liberalismo con la superación de las guerras civiles religiosas, el liberalismo de Rawls no pertenece, a diferencia del de Isaiah Berlin o Richard Rorty, a la tradición del liberalismo del miedo, al liberalismo en cuanto ideario cuya trama es la abominación de la crueldad. Para Rawls, las prácticas históricas de tolerancia vienen a demostrar lo fructífero de la estrategia de excluir las convicciones religiosas (u otras igualmente capaces de generar discordia) de entre las razones susceptibles de servir como base de la legitimidad política

12 En este sentido, las expectativas del liberalismo político rawlsiano respecto a los destinata rios del orden que prescribe son muy distintas a las de la Carta sobre la tolerancia de Locke, a la que tanto debe. Ello no es de extrañar si tomamos en cuenta que Locke escribe no mucho después de una guerra civil con componente religioso. 
allí donde la sociedad no comparte un mismo credo o doctrina acerca de la vida buena.

De hecho, Rawls (1985, pp. 391-95; 2002, pp. 23-27) vincula la reflexión sobre la tolerancia con otra acerca del papel que corresponde a la filosofía política cuando se da una persistente controversia sobre cuestiones políticas básicas, como son el significado de la libertad y la igualdad y su valor relativo. Esto explica que, no obstante el destacado papel de la tolerancia como virtud en el liberalismo político, cuando consideramos la teoría en su conjunto la idea de tolerancia aparece ante todo como una fórmula para implantar un orden político estable en una sociedad dividida por sus convicciones morales. En otras palabras: el encaje de la reflexión sobre la tolerancia dentro de una reflexión más amplia acerca de la justicia nos permite entender que desde el punto de vista de quienes reflexionamos sobre el liberalismo político de Rawls y de los lectores de su obra, la tolerancia se presente más que nada como un criterio básico o principio de legitimidad ${ }^{13}$. Lo cual no afecta de ningún modo a la consideración de la tolerancia como un rasgo básico de la personalidad moral de los ciudadanos de una sociedad bien ordenada, para quienes son acordados los principios de la justicia. Un rasgo que también ha de caracterizar las diferentes doctrinas cosmovisivas cuya aprobación cuenta para la aprobación (en un consenso por superposición) de tales principios.

\subsection{El principio de tolerancia como principio histórico}

La identificación de la tolerancia como principio político recoge, al igual que ocurre con la tolerancia como virtud, una parte de la comprensión común de ésta. Como señala Cohen $(1994$, p. 1505, en el mismo sentido, Richards, 1996, p. 135), es convencional entender la tolerancia como un «principio político sustantivo que condena la imposición de una forma autoritaria de creencia religiosa o, en una acepción más amplia, una forma autoritaria de moralidad personal».

Ciertamente, emplear el término tolerancia para referirse a la norma de organización y funcionamiento del Estado conlleva una abstracción de las más que notables diferencias que existen entre las primeras formas modernas de emancipación de los fines políticos respecto de la ética religiosa y el modo en que esta emancipación se reproduce en las democracias liberales contemporáneas. En contraste con lo usual en la primera modernidad, en las democracias de hoy en día la autonomía de la política no pasa por el sacrificio de las convicciones de unas autoridades confesionalmente comprometidas con una fe concreta. Tal separación entre política y convicciones parti-

13 Cohen (1994, p. 1505). Sobre la diferencia entre el punto de vista de las partes, los ciudadanos y quienes evalúan la concepción de la justicia, véase Rawls (1980, pp. 320-321 [153]; PL, I, $\S 4.3$ ). 
culares no se consigue gracias a tolerar (limitadamente) el error de alguna minoría, sino mediante un régimen de derechos. Pero para unas sociedades que, como la europea de los siglos XVII y XVIII y la de los primeros colonos norteamericanos, tenían en la fe su bien más preciado, el final de un régimen de intolerancia representó un hecho tan palpable y digno de celebración que por comparación el tránsito de un régimen de tolerancia a otro de igualdad de derechos bien ha podido considerarse tan sólo como una cuestión de detalle. Tanto más cuando el advenimiento de la tolerancia supuso el cese de persecuciones o de guerras civiles. Esto explicaría que, a pesar del anacronismo que supone, los herederos de aquellas sociedades puedan seguir refiriéndose como tolerancia o principio de tolerancia a cualquier modo institucional de definir los objetivos políticos que evite la sujeción de éstos a los valores religiosos o éticos de una comunidad particular.

En el ámbito anglosajón, el apelativo de tolerancia para cualquier régimen excluyente de la imposición de creencias sectarias se ve además apoyado por varias circunstancias. Comenzando por el Reino Unido, la Toleration Act de 1689 estableció el carácter no exclusivo de la Iglesia anglicana, con la cual, en todo caso, la corona sigue manteniendo un compromiso oficial. Y esta norma no ha sido abrogada por otra de carácter más general, sino que se han ido añadiendo disposiciones complementarias relativas a los derechos de los católicos y los judíos, entre finales del siglo XVIII y mediados del XIX (Scarman, 1987, p. 50).

En los Estados Unidos, a pesar de que la influencia de Madison evitó cualquier referencia a la tolerancia en el texto de la Primera Enmienda de la Constitución, la libertad de conciencia que allí se proclama se plasma en dos obligaciones del poder político: la de no dictar leyes que establezcan un credo oficial y la de no dictar leyes que prohíban el libre ejercicio religioso. Este enfoque referido a los límites del poder antes que a los derechos subjetivos de las personas debe explicarse por la gran autoridad que la Carta sobre la tolerancia ejerció sobre todo el pensamiento religioso y político norteamericano del siglo XVIII referente a la libertad religiosa; autoridad que se vio reforzada por la consciente reelaboración de las ideas lockeanas realizada por Jefferson y Madison. A partir de estas notables influencias, la teoría de Locke sobre la tolerancia ha configurado en aspectos sustanciales la jurisprudencia estadounidense en materia de libertad de conciencia. Las concepciones jurídicas de la libertad de expresión, el derecho a la intimidad e incluso la discriminación racial se asientan sobre diversas ideas originales de Locke. Ideas como la de radicar la legitimidad de la tolerancia en el contractualismo, la de que no existe una única interpretación correcta de las escrituras o la de que el poder civil debe limitarse a perseguir los fines que le son propios. No es de extrañar, por tanto, que la teoría constitucional estadounidense se refiera a estos asuntos indistintamente como libertades, derechos o tolerancia de pensamiento, expresión y acción. 
Ahora bien, de entre todas las influyentes ideas de cuño lockeano mencionadas, una debe destacarse por captar, como ninguna otra, el ideal moral que inspira la protección de la libertad de conciencia en la Constitución de los Estados Unidos: la de que es ilegítimo forzar unas convicciones que no son aceptables por cualquier persona libre y racional. Esta idea se asienta en el presupuesto de que lo propio de una persona así es que quiera retener la capacidad de conformar y modificar las propias creencias y pensamientos libre y racionalmente; en especial, las convicciones relativas a materias que sólo pueden ser objeto de un conocimiento probabilístico pero que resultan de la máxima importancia para los individuos. En otras palabras, si una idea de Locke ha contribuido a configurar el régimen estadounidense de libertad de conciencia, ésa ha sido la de que las creencias sectarias no pueden imponerse tan sólo en razón de la certidumbre que provee la lealtad e identificación con un grupo. El correlato de esta idea es que las creencias sólo merecen inspirar la acción de los poderes públicos si vienen a satisfacer lo que Locke denomina «intereses civiles», es decir, aquellos bienes que cualquier persona razonable puede desear. Esta destacada tesis de Locke conforma el principio de la tolerancia que es básico del constitucionalismo estadounidense y al que Rawls acude para solucionar el problema de hallar un criterio de legitimidad aceptable en un contexto de pluralismo moral (sobre lo anterior, véase Richards, 1986 , caps. 4 y 5; PL, pp. 97-105 [128-136]).

\section{7. «Aplicar el principio de tolerancia a la filosofía misma»}

El modo en que Rawls se sirve del principio de tolerancia para hacer frente al desafío que la diversidad de cosmovisiones filosóficas y religiosas representa para la estabilidad del orden político es paralelo a cómo en Una Teoría de la Justicia manejaba la teoría tradicional del contrato social. Allí Rawls proponía un criterio de justificación para los principios básicos del orden social y político a partir de «generalizar y llevar a un mayor nivel de abstracción la teoría tradicional del contrato social [Rawls, 1971, pp. viii, xv $[10,12]] »$. En el liberalismo político también es la generalización y la abstracción, pero del principio de tolerancia, lo que hace posible establecer las pautas que deben regir las instituciones sociales y políticas fundamentales (Cohen, 1994, p. 1505). Rawls denomina a esta operación de generalización y abstracción «aplicar el principio de tolerancia a la filosofía misma», porque es de su fundamento y radicalmente y no sólo de la organización institucional del poder o de la actuación de éste de donde deben expurgarse todas las pretensiones de verdad o corrección sectarias (metafísicas).

Ya en Una Teoría de la Justicia Rawls había dado pasos en el sentido de generalizar el principio de tolerancia, al estipularse allí la generalización del principio de tolerancia religiosa como patrón de la distribución de libertades. 
El liberalismo político extiende aún más el ámbito del principio de tolerancia al verse condicionado por éste también el patrón decisivo de la distribución de los beneficios. Pero, sobre todo, el segundo Rawls significa claridad y contundencia en la afirmación de que las reglas para la estructura básica de una sociedad democrática no pueden venir dadas por ninguna doctrina que estipule un ideal general para la vida humana, incluyendo la conducta no política (por ninguna doctrina comprehensiva, en palabras de Rawls). La razón por la que el principio de tolerancia se alza en pilar del orden sociopolítico es ya a estas alturas conocida por el lector: la evidencia de que es un rasgo normal de las sociedades democráticas contemporáneas el que encontremos en ellas una pluralidad de cosmovisiones filosóficas y religiosas cuya verdad o falsedad no puede dirimirse terminantemente por procedimientos racionales y que de hecho divide a los miembros de estas sociedades.

Si no es en una doctrina comprehensiva, ¿dónde puede radicar el fundamento de una concepción de la justicia para una sociedad democrática? La respuesta de Rawls es que en las ideas esenciales de las instituciones políticas de un régimen constitucional democrático y de las tradiciones públicas de su interpretación. Los ciudadanos de una sociedad democrática contemporánea tienen en común su condición de miembros de una organización política que funciona con arreglo a ciertas prácticas, las cuales a su vez responden a los valores de una tradición ideológica que es la liberal. Estos valores liberales constituyen los axiomas de la teoría política rawlsiana. Rawls únicamente los somete a examen en lo que respecta a su integridad como valores políticos. Esto es, la concepción liberal de la sociedad, de la persona en cuanto ser social o de la legitimidad, pueden servir de base pública de justificación en cualquiera de sus interpretaciones que no presupongan ninguna doctrina comprehensiva. Incluso si incorporan algunos elementos comprehensivos, cualquier interpretación de las referidas concepciones puede ser válida, mientras otorgue prioridad a los valores políticos frente a otros valores en conflicto. Por este entronque con una tradición política - la tradición liberal- y por la buscada independencia de cualquier doctrina comprehensiva, la concepción de la justicia que propone Rawls se caracteriza como una concepción política. La esperanza de Rawls es además que esta concepción política de la justicia pueda ser objeto de un consenso por superposición, esto es, de un consenso del que participen todas las doctrinas filosóficas y religiosas que puede esperarse que persistan y obtengan adhesiones en una sociedad democrática más o menos justa (Rawls, 1985, pp. 388-390, 394-395; PL, I, \& 1.3, p. 155 [187]).

Lo que se persigue con esta aplicación de la tolerancia a la filosofía (política) misma es evitar que la justificación del poder pueda venir dada por algún valor o esquema de valores que no puedan ser compartidos por quienes han de verse sujetos a tal poder. Se trata de no caer, por tanto, en la imposición de unos valores y del régimen político por ellos soportado. De lo 
contrario nos encontraríamos con la inestabilidad de tal régimen, en dos sentidos: por un lado, en el sentido funcional o estratégico de debilidad estructural del orden político, esto es, provocaría inestabilidad el hecho de que la configuración del poder no coincida con las convicciones de los ciudadanos al respecto. Por otro lado, la aplicación de la tolerancia a la filosofía busca que no se produzca inestabilidad de carácter normativo: una democracia liberal no puede asentar su legitimidad en el desprecio de valores liberales básicos, como pueda ser el de que las personas son libres e iguales, independientemente de sus convicciones.

\section{2. ¿TOLERANCIA EN UNA DEMOCRACIA CONSTITUCIONAL?}

\section{1. Virtud y principio de tolerancia en la democracia constitucional, según se desprende del liberalismo político}

Han quedado identificadas como centrales para el liberalismo político de Rawls dos nociones de tolerancia què coinciden con dos maneras en las que habitualmente se entiende ésta: una es la de tolerancia como virtud, la cual se ha definido como una disposición a no intervenir contra ideas o prácticas que lesionan razonablemente nuestras convicciones. Esta virtud, piensa Rawls, se halla entre las prácticas que conforman la personalidad moral de los miembros de las sociedades democráticas y por eso determina la elección de los principios de la justicia que realizan las partes en la posición original, y es requisito de la ciudadanía democrática.

La otra noción de tolerancia presente en la obra de Rawls, eje del giro teórico que supone el liberalismo político respecto a su obra anterior y por ello más fundamental, es la de tolerancia como principio de legitimidad del orden político. Este principio prescribe que en ningún caso se impongan convicciones morales o religiosas mediante el empleo del poder público. El significado de tal prohibición va asociado a una cierta idea de la personalidad moral de quienes integran la sociedad política. Según Rawls, debe esperarse de un ciudadano la facultad de conformar y modificar las propias convicciones (racionalidad) y la disposición a proponer y aceptar términos equitativos de cooperación social (razonabilidad). Por ello se considerará impuesta toda aquella obligación que no venga sustentada por lo que cualquier persona racional y razonable admitiría como buenas razones. Lo cual excluye emplear en el fundamento del orden político pretensiones de verdad o corrección acerca de las cuales la discrepancia no quepa atribuirla necesariamente a un error moral o epistemológico. Y de la misma personalidad moral que emana una justificación del orden político con arreglo al principio de tolerancia, también se deriva un modelo de comportamiento cívico ajustado al mismo principio: la virtud de la tolerancia. 
La relación entre principio y virtud de tolerancia es, por lo demás, estrecha:

En primer lugar, un poder político cuyo fundamento y acción vengan dados por creencias sectarias (esto es, que no se rija por el principio de tolerancia en estos aspectos) no puede ser aceptado como legítimo por aquellos cuya personalidad moral incorpora la virtud de la tolerancia. Un tipo de personalidad moral que según Rawls es tan característico de los miembros de las sociedades democráticas como la persistencia en ellas de diferencias en materia moral y religiosa.

En segundo lugar, el carácter razonable del pluralismo filosófico, moral y religioso propio de las sociedades democráticas, además de una variedad de doctrinas comprehensivas razonables (esto es, tolerantes), supone que las razones por las que discrepan tales doctrinas no son debidas ni a la ignorancia ni a la maldad, sino a limitaciones de la razón humana. Esto convierte en inaceptables, normativamente hablando, tanto un comportamiento personal intolerante como un régimen político sectario.

En tercer lugar, la estabilidad de un régimen liberal depende de ciertas disposiciones de los ciudadanos, entre las cuales se encuentran tanto la participación del valor de la tolerancia como su puesta en práctica. Debido a la importancia de estas actitudes y conductas, el reconocimiento pleno de la condición de ciudadano se encuentra supeditado a que se manifieste la virtud de la tolerancia. Y se entiende legítimo que se estimule la adquisición de esta virtud y se desaliente el seguimiento de concepciones del bien incompatibles con ella ( $P L$, pp. xviii, 36-37 [14, 66-67]; V, §§ 6-7).

\section{2. Los deberes de tolerancia en una democracia constitucional}

A pesar de las consideraciones anteriores, habida cuenta del carácter constitucional democrático del régimen político que Rawls propugna y la vigencia en este régimen (como ideal aceptado socialmente y plasmado jurídicamente de algún modo) del principio de tolerancia, cabe cuestionar la pertinencia de otorgar un lugar destacado a la virtud de la tolerancia en el liberalismo político.

Dentro de una democracia liberal, la esfera pública y el poder político pertenecen idealmente a todos los ciudadanos por igual, con independencia de cuáles sean sus creencias o preferencias en el modo de vivir. Esto supone que nadie puede ejercer una autoridad pública guiándose por su personal criterio moral acerca de lo correcto y lo censurable. Más bien, la legitimidad de una actuación política está condicionada a que se ajuste a ciertos principios compartidos por el común de la ciudadanía, con prioridad de los mandatos colectivos expresados en el ordenamiento jurídico y de modo singular en la Constitución. Un elemento básico de tal orden jurídico es un sistema de iguales 
derechos para todos los ciudadanos, que garantice a éstos una amplia libertad de creencias y acción. Y por este motivo la imposición de trabas a una práctica social o su prohibición sólo puede ser legítima si estos derechos son respetados. Por su parte, el juicio de conformidad jurídica de una conducta restrictiva de libertades depende de una operación cognoscitiva que en principio es ajena a las inclinaciones éticas de quien lo realiza. Además, tal juicio de corrección jurídica de una acción limitativa de las libertades no puede emitirlo cualquiera: la eficaz protección de los derechos, y su ajustada definición a la voluntad de todos los ciudadanos por igual, demandan que sólo los poderes públicos sean competentes para hacerlo, y ello únicamente en supuestos y mediante procedimientos establecidos de manera democrática ${ }^{14}$.

En este contexto no parece que dejar de intervenir contra aquello que razonablemente lesiona las propias convicciones pueda constituir la pieza clave de la articulación de la unidad política con el pluralismo moral. Y es que en un régimen democrático liberal ya constituido, el espacio de lo que públicamente cabe considerar que lesiona con razón nuestras convicciones, no menos que la competencia para actuar legítimamente contra una conducta, están limitados por el valor de la libertad personal, el principio de tolerancia y la protección jurídica de la que éstos gozan. Desde el punto de vista institucional y de los principios públicos, la democracia constitucional no confía a la virtud de ciudadanos y gobernantes, sino al sistema de los derechos garantizados por la fuerza del Estado, la protección y la resolución de conflictos morales, religiosos y de estilos de vida (De Lucas, 1992, 1996; Martínez de Pisón, 2000).

Rawls no se plantea la objeción anterior, pero cabe extraer una respuesta a ella de su teoría de la tolerancia que nos da pie a exponer un aspecto importante de esta última. Rawls tiene gran confianza en el Derecho en cuanto mecanismo de resolución de conflictos, hasta el punto de adoptar el razonamiento judicial como modelo de razonamiento público. Pero esto no le impide ser consciente de la dependencia que el Derecho mantiene respecto a la virtud cívica al efecto de lograr que el ordenamiento jurídico exprese efectivamente la autonomía colectiva. El liberalismo político no da por sentado que el Derecho de una democracia liberal plasme siempre y efectivamente el ejercicio del poder político por parte de ciudadanos que se relacionan entre sí como personas libres e iguales, sin discriminación por razón de creencias. Y como quiera que considera fundamental para la estabilidad de una democracia liberal en un contexto de pluralismo cosmovisivo que el Derecho se identifique con la citada voluntad colectiva, condiciona la legitimidad de las normas jurídicas que desarrollan «esencias constitucionales» o cuestiones de justicia básica a que se cumpla el deber moral de civilidad de actuar según la razón pública.

14 PL, VI, VIII; Rawls (1997, p. 577 [160]). Con él coincide Habermas (1998a, esp. caps. III y IV). Véase, igualmente, Honneth (1997, pp. 135-143). 
Tal deber de civilidad conlleva que en las deliberaciones dirigidas a fijar los términos de las referidas normas los legisladores, gobernantes, funcionarios, candidatos a cargos públicos y ciudadanía en general se apoyen únicamente en la interpretación de la concepción política de la justicia que consideran más razonable, compuesta en todo caso empleando métodos de indagación no controvertidos. Aquí, el criterio determinante de la razonabilidad es la reciprocidad. Lo cual supone que «cuando unos ciudadanos proponen unos términos como los más razonables para la justa cooperación, quienes los proponen también tienen que considerar que para los otros resulte, al menos, razonable aceptarlos como ciudadanos libres e iguales y no dominados o manipulados o presionados por una condición política o social inferior» (Rawls, 1997, p. 578 [161]). Por eso, en los debates y actuaciones en el foro público acerca de las «esencias constitucionales» y cuestiones de justicia básica - y seguramente en la mayoría de los asuntos, piensa Rawls, aunque no se atreve a afirmarlo- debe manejarse la razón pública para justificar las propias pretensiones.

Cuando Rawls habla de foro público, se refiere a actuaciones como las de los partidos políticos o grupos que les apoyan en las campañas electorales, los legisladores en el parlamento y en las motivaciones de las leyes o el ejecutivo en sus manifestaciones oficiales y disposiciones jurídicas. También los ciudadanos deben hacer lo posible con su voto y otras medidas de presión legítimas para que los cargos y funcionarios públicos actúen conforme a la razón en los supuestos citados ( $P L$, VI, $\S \S 1-2 ; 1997$, cap. 1). De no ser así, sin un dedicado cultivo por parte de los ciudadanos de la razón pública, y la vitalidad de la cultura política que de ello se desprende, la fractura social y la hostilidad entre doctrinas estaría, según Rawls, abonada. Los ciudadanos «podrían caer fácilmente en la amargura y el resentimiento» si percibieran que el puente de la razón pública ha dejado de estar tendido (Rawls, 1997, p. 610 [199]).

Además del deber de apelar a la razón pública, el ideal de ciudadanía está integrado por la disposición a escuchar a los demás, así como a ser ecuánimes al evaluar cuándo resultaría razonable acomodarnos a sus puntos de vista. El poder en una democracia constitucional no puede ejercerse como poder colectivo si los ciudadanos no se prestan al diálogo y al acuerdo. Por eso es de esperar de tales ciudadanos que - como plantean Gutman y Thopsom, a quienes Rawls remite sobre este asunto- mantengan abierta la posibilidad de adoptar la postura del oponente; y también que procuren la economía del desacuerdo moral, esto es, que busquen puntos de convergencia entre la propia visión de las cosas y la de otros ciudadanos cuyas ópticas rechazan.

Junto a todas estas prácticas, en las condiciones de persistente conflicto moral características de las democracias contemporáneas, el entendimiento necesario para que la democracia prospere pasa porque se reconozca rango 
moral, y no sólo un reconocimiento interesado económica o políticamente, a aquellas posiciones de las que se discrepa ( $P L, \mathrm{VI}, \S 2$ y n. 4; Gutman y Thompson, 1990, pp. 134-142). El liberalismo de Rawls otorga a este último aspecto especial importancia. Y así constituye una novedad respecto a la Teoría de la Justicia que la «disposición a proponer y aceptar términos equitativos de cooperación social» en que consiste básicamente el sentido de la justicia implique, no ya admitir la categoría moral de las concepciones del mundo que son distintas a las propias, sino incluso su posible verdad o corrección. Sin esto último, sin lo que Rawls denomina la admisión de las cargas del juicio, entiende Rawls que no puede una persona renunciar en conciencia a fundamentar el orden político en sus convicciones particulares.

\subsection{La crítica al exceso de definición de los deberes de tolerancia}

La correspondencia del deber de apelar a la razón pública con la virtud de la tolerancia no parece difícil de apreciar: este deber comporta una autolimitación en el manejo del poder político del que los ciudadanos disponen en una democracia, de manera que se renuncia a radicar la justificación de tal poder en los propios valores filosóficos y religiosos. La misma correspondencia con la tolerancia puede predicarse de las obligaciones de escuchar a los demás, mostrarse equitativo en decidir cuándo acomodarse a sus posiciones y buscar puntos de convergencia. Además, por lo expuesto acerca de cómo la estabilidad de la democracia depende de que se cumplan tales obligaciones que también integran el deber de civilidad, está claro que nos hallamos ante virtudes públicas.

Se ha objetado que Rawls plantee como un deber cívico el apelar a la razón pública en el foro público siempre que se traten en él «esencias constitucionales» o cuestiones de justicia básica. Los críticos no dudan que la concepción política postulada por Rawls sea normalmente la más apta para lograr un amplio acuerdo sobre las citadas cuestiones políticas; una aptitud que provendría de la adecuada definición de las identidades e intereses de quienes componen una sociedad democrática y pluralista que tal concepción ofrece. Sin embargo, piensan autores como Thomas McCarthy (1997, pp. 51-53) o Jürgen Habermas (2000c, p. 208), la extensión de los intereses generalizables y el nivel de abstracción con que se presentan las identidades e intereses son cuestiones que, como regla general, debieran dejarse abiertas. Abiertas al menos en el ámbito de la generación de la legitimidad. La preservación del capital de legitimidad generado, de la que se ocupa el discurso jurídico, sí que necesita de un alto grado de certeza para persistir como medio básico de integración de una sociedad moderna.

El propio Rawls admite la utilidad de que en el foro público se expresen las razones en virtud de las cuales se apoyan los valores políticos fundamen- 
tales, pues ello sirve para disipar las dudas acerca de la aceptación de tales valores por parte de una doctrina comprehensiva dada (PL, p. 249 [284]). Del mismo modo reconoce las bondades de manifestar las propias convicciones globales en sus propios términos o de argumentar a partir de lo que alguien piensa que son las creencias globales ajenas junto a la apelación a la razón pública: con todas estas prácticas se promueve el conocimiento público de las diferentes doctrinas comprehensivas razonables, se hace ver la compatibilidad y proximidad de tales doctrinas respecto a la concepción política de la justicia y se genera, en suma, confianza mutua (Rawls, 1997, cap. 4). A estos argumentos cabe añadir que el posicionamiento sobre un asunto político controvertido en términos comprehensivos puede abrir los ojos de algunos ciudadanos acerca de aspectos hasta un cierto momento descuidados. Y que con eso se favorece la inclusividad de la formación de la voluntad popular aun cuando la cuestión no deba ser decidida por consideraciones emanadas de ninguna cosmovisión particular (Habermas, 2003, p. 9).

A Rawls no se le escapa que determinados argumentos comprehensivos pueden ser incluso decisivos de que se llegue a un acuerdo sobre cuestiones constitucionales y de justicia básica. De hecho, reconoce el valor que los alegatos comprehensivos de los abolicionistas o de Martin Luther King tuvieron en la superación de injusticias incompatibles con una democracia liberal $(P L, \S 8.3)$. Pudiera ocurrir, piensa Rawls, «que para llegar a una sociedad bien ordenada, en la que la discusión pública consiste principalmente en una apelación a los valores políticos, las condiciones históricas previas requieren la invocación de razones comprehensivas que robustecieran aquellos valores», lo cual «parece más probable cuando no hay sino unas pocas doctrinas comprehensivas fuertemente respaldadas y en varios puntos similares entre sí» ( $P L$, p. 251, n. 41 [287J).

Considerando, por una parte, los supuestos en los que el liberalismo político reconoce legítima la alegación de argumentos comprehensivos y particularmente lo dudoso que resulta que alguna de las sociedades existentes pueda declararse como una «sociedad bien ordenada» ${ }^{15}$. $\mathrm{Y}$ tomando en cuenta, por otro lado, la dificultad de concebir mejor base de acuerdo para los ciudadanos de una sociedad bien ordenada que una concepción política de la justicia del estilo de la propuesta por Rawls. La conclusión debida es que apenas si hallamos discrepancias prácticas entre Rawls y los críticos del deber de apelar a la razón pública: uno y otros estarían de acuerdo en la necesidad práctica de justificar las posiciones relativas a cuestiones constitucionales y de justicia básica con arreglo a la razón pública, además de hacer valer cualesquiera otras consideraciones comprehensivas que pudieran

15 Decir que una sociedad está bien ordenada comporta entre otras cosas que se trate de «una sociedad en la que cada uno acepta, y sabe que todo el mundo acepta, exactamente, los mismos principios de la justicia» y que «su estructura básica... satisface esos principios de un modo público y notorio» $(P L$, p. $35[65-66])$. 
apoyar la gestación de un amplio acuerdo acerca de estas cuestiones. No obstante, cabe conceder a los críticos del deber de apelar a la razón pública la ventaja de que no plantean tal deber como un correlato inexorable de la adhesión a una tradición, la liberal, sino como un medio generalmente eficaz para lograr un acuerdo de todos los ciudadanos sobre asuntos políticos fundamentales. Con ello, además de abrirse a la contingencia de que aparezcan mejores opciones - virtud que no es menor en sociedades como las nuestras, que tienen en el cambio constante un rasgo básico-, se conjura el riesgo de interpretaciones integristas del léxico liberal-democrático. Es decir, el riesgo de que pueda postularse que los límites al entendimiento público se encuentran establecidos por una interpretación tradicional de la tradición liberal.

Al igual que la obligación de apelar a la razón pública, también ha sido criticado el modo en que Rawls concibe otra de las obligaciones ciudadanas relacionadas con la tolerancia por lo innecesariamente restrictivo (intolerante) que resulta. Me refiero a la obligación de mostrarse dispuesto o dispuesta a admitir el rango moral de las cosmovisiones razonables de los demás. Una obligación que conlleva «la disposición a reconocer las cargas del juicio y a aceptar sus consecuencias a la hora de usar la razón pública en la tarea de orientar el legítimo ejercicio del poder político en un régimen constitucional». Tal disposición constituye el segundo aspecto básico de lo razonable, esencial para la justificación de la tolerancia en el esquema del liberalismo político $\left(P L\right.$, p. $54[85 J)^{16}$.

Pues bien, ciertamente para alcanzar un acuerdo equitativo acerca de los términos de la cooperación social, en una sociedad pluralista es preciso que la generalidad de los ciudadanos reconozca el igual valor ético que para las diferentes personas tienen sus respectivas concepciones existenciales. Sólo así podrá acordarse una fórmula de cooperación social que resulte equitativa en un sentido fundamental: el del reconocimiento del valor que para las personas tienen aquellas prácticas sociales (lenguas, tradiciones, religiones, estilos de vida...) que les proveen de recursos para formar y mantener su identidad personal. La estabilidad de la cooperación social exige, por su parte, que los pactos alcanzados al respecto se encuentren cognitivamente conectados con las diversas doctrinas comprehensivas compartidas por los ciudadanos ${ }^{17}$.

Sin embargo, ni el referido reconocimiento del igual valor ético relativo, ni la articulación entre concepciones existenciales y la concepción política de la justicia tienen necesariamente que provenir de la admisión de las cargas del juicio como las entiende Rawls. A una conciencia secularizada, el catálogo de cargas del juicio le ofrece buenas razones para asumir la igual prioridad que para cada cual tiene su propia visión del mundo. Pero para

16 Véase supra el parágrafo 1.2 de este trabajo.

${ }_{17}$ Esto también lo sostiene Habermas (2003, p. 12). 
quienes mantienen una concepción existencial que depende de verdades de fe o de concepciones metafísicas que reclaman valor universal, la integridad de su ethos se sustenta en una consideración de otras formas de vida no ya como distintas, sino como erradas. Las formas de vida vinculadas a minorías nacionales, étnicas o descendientes de culturas de esclavos pueden tener aún más difícil relativizar el valor de su propio ethos que las cosmovisiones religiosas que cuentan con los recursos conceptuales de una religión universal (Habermas, 2003, p. 9).

Incluso una doctrina comprehensiva que da por cierto el error de otras concepciones del mundo puede contener recursos suficientes para admitir tres afirmaciones que sí cabe considerar presupuestos de la vida en común en una sociedad liberal: en primer lugar, que se debe respetar el derecho de cada cual a abrazar y revisar voluntariamente su propia concepción existencial; en segundo término, que se puede cooperar socialmente con quienes no comparten la propia cosmovisión, a pesar del error en que puedan hallarse; y por último, que para lograr la cooperación referida se deben justificar las propias posiciones de manera que puedan ser compartidas por todos los miembros de una misma sociedad.

La historia de las justificaciones teológicas de la tolerancia nos habla de diversas aproximaciones a cómo los dos primeros presupuestos pueden darse sin necesidad de reconocer las cargas de la razón. Lo mismo puede predicarse de la comprensión imaginativa o imaginación reconstructiva defendida por Isaiah Berlin: quizás no consideremos al otro o la otra razonable en sus planteamientos, pero podemos llegar a entender la prioridad que otorgan a su esquema particular de valores y confiar en ellos como unos otros-comonosotros desde la experiencia de lo que entraña para nosotros nuestro propio esquema (véase Díaz-Urmeneta, 1994, pp. 283 ss.). La depuración del lenguaje de los fundamentos del orden social para hacerlo más inclusivo no depende tampoco del reconocimiento de las cargas del juicio del modo planteado por Rawls: es algo que encontramos planteado, por ejemplo, en las justificaciones de la tolerancia basadas en la caridad cristiana a partir de Erasmo de Roterdam o en la separación entre lo civil y lo religioso postulada por la doctrina protestante, especialmente de las sectas menores.

Con todo, lo más frecuente en las sociedades contemporáneas es que doctrinas en origen comprehensivas sean adoptadas por los ciudadanos como parcialmente comprehensivas, como material del que se sirven para construir o asumir concepciones del mundo híbridas o modulares. Por ello la compatibilidad de una doctrina comprehensiva con un régimen político liberal no depende de las versiones originales u oficiales de tal doctrina. Es más, la naturaleza adaptativa que presenta este ensamblaje de concepciones existenciales sirve a menudo para depurar en la práctica los aspectos menos reconciliables con la tradición liberal. $\mathrm{Y}$ así alguien puede, por ejemplo, declararse católico (como lo hace el 80 por 100 de los españoles), no alber- 
gar dudas acerca de la existencia de Dios y, simultáneamente, aprobar la eutanasia y estimar la homosexualidad como una opción personal tan respetable como la heterosexualidad, como manifiestan el 62 y el 65 por 100 de los españoles, respectivamente.

La conclusión que debe extraerse de las anteriores observaciones es que el concepto de desacuerdo razonable resulta más inclusivo, más abierto a ser compartido por distintas doctrinas comprehensivas y por ello más adecuado al pluralismo característico de las sociedades democráticas modernas cuando se prescinde de asociarlo a un catálogo de las cargas del juicio. Un catálogo éste que no capta adecuadamente el sentido político normativo de la idea de los desacuerdos razonables. Este sentido es primordialmente el de justificar el respeto debido a la facultad que cada cual tiene para de forma voluntaria abrazar y revisar su propia concepción existencial. Sin embargo, el catálogo de las cargas de juicio no aporta por sí solo tal justificación, ya que hace falta tener en cuenta que las cargas del juicio forman parte de un ideal de ciudadanía para no concluir que estas cargas también afectan al valor de nociones ético-políticas básicas como la del respeto a decidir sobre la propia visión del mundo. El otro servicio fundamental que presta la idea de que existen desacuerdos razonables al liberalismo político es ofrecer una pauta normativa para discriminar entre aquel pluralismo cosmovisivo que resulta compatible con una democracia liberal y aquel que no. Pues bien, esta doble tarea político-normativa desempeñada por los desacuerdos razonables en el liberalismo político puede cumplirse de manera menos controvertida que con el requisito de admitir las cargas del juicio exigiendo a los ciudadanos que asuman los tres presupuestos de la vida en común en una sociedad liberal antes señalados.

\section{4. De nuevo sobre el lugar de la virtud de la tolerancia en una democracia constitucional}

Ha sido expuesta la posición de Rawls acerca de la necesidad que tiene una democracia constitucional de que sus ciudadanos se conduzcan con arreglo a la virtud de la tolerancia. Según lo visto, tal conducta virtuosa sería imprescindible para que el ordenamiento jurídico refleje efectivamente el ejercicio del poder político por parte ciudadanos que se relacionan entre sí como personas libres e iguales y sin discriminación por razón de creencias. Gracias a la virtud de la tolerancia, personas comprometidas con doctrinas comprehensivas distintas y hasta contrapuestas renunciarían a que de sus convicciones particulares deban emanar los principios fundamentales regulativos de la estructura básica de la sociedad y sus reglas de interpretación. Y ello a pesar de tratarse de doctrinas que racionalmente no son refutables, por lo cual su falta de realización conlleva una lesión razonable de convicciones 
aunque su verdad o corrección no quepa establecerlas de modo universal. Expresada en la razonabilidad y en las diversas manifestaciones del deber de civilidad, la tolerancia sería para Rawls una pieza importante de la articulación de la unidad política con el pluralismo moral.

Pero cabe seguir preguntándose: en una democracia constitucional, que se conduce conforme a una concepción política de la justicia como la que defiende Rawls, ¿cabría más uso legítimo del poder que aquel que se ajusta al principio de tolerancia en la manera en que éste se encuentra reconocido por el ordenamiento jurídico? ¿Realmente se tolera que el orden social no se ajuste a convicciones morales o religiosas particulares cuando conforme a los valores políticos fundamentales no existe competencia adecuada para hacer nada distinto? ${ }^{18}$

Para valorar este planteamiento de cuño kantiano de que no hay lugar público para la tolerancia allí donde el poder político se halla constitutivamente vinculado con la protección del pluralismo ${ }^{19}$ hay que practicar una distinción:

\section{4. 1. Tolerancia cero: aspectos de la diversidad social que gozan de protección jurídica taxativa}

Por un lado tenemos aquel conjunto de tareas del poder político orientado a proteger la diversidad de concepciones del bien en aspectos que se consideran esenciales. Rawls identifica este espacio de autoridad con los derechos y libertades básicos, como la libertad de culto, asociación, expresión o participación política, tomados aisladamente de la igualdad de oportunidades. Estas instituciones, piensa Rawls, «sólo pueden definirse de una manera aun si con pequeñas variaciones». Y es una afirmación desde luego correcta en lo referente al núcleo duro de los referidos derechos. Es decir, en cuanto a aquel ámbito de libertad que de no ser respetado supondría una inequívoca violación de derechos de conformidad con los ideales regulativos de la correspondiente comunidad de juristas o ciudadanos bien informados. Una comunidad que a estos efectos sería la abarcada por «los regímenes libres» $(P L$, p. $228[263])$.

\footnotetext{
18 Exigen que concurra la circunstancia de competencia adecuada para reconocer que se está ante un supuesto de tolerancia, entre otros, Mendus (1989, p. 9) y Garzón Valdés (1992, p. 18). Horton (1996, p. 29) sostiene, a mi juicio correctamente, que para la identificación de la tolerancia como virtud interesa considerar la competencia no únicamente como competencia efectiva, sino también como hipótesis contrafáctica.

19 Para Kant (1975, p. 35, y 1989 , pp. $48-49$ y 143), no hay lugar para el permiso ni la benevolencia cuando afecta al derecho del hombre a la autonomía, por lo que rechaza como «pretencioso" el «sustantivo de tolerancia». Una opinión similar la expresaron Thomas Paine, James Madison, el conde de Mirabeau o Goethe; véase Fetscher (1994, p. 19) y Solar Cayón (1996, pp. 69-70). La crítica a la vigencia de la tolerancia en el Estado democrático de Derecho de De Lucas $(1992,1996)$ y Martínez de Pisón (2001) se hacen eco también de la idea referida.
} 
Además, por encima del mínimo común aceptado por todos los sistemas político-jurídicos liberales, en cada uno de esos sistemas pueden haberse asentado interpretaciones más amplias de algunas libertades concernientes tanto a aspectos negativos como positivos de éstas (por ejemplo, el derecho a recibir educación básica en España), que tampoco serían discutidas por ningún operador jurídico competente o ciudadano bien informado. En el esquema del liberalismo político de Rawls, este significado más amplio de algunas libertades - que conlleva restricciones a la soberanía popular expresada en la legislación - puede ser establecido en la etapa de la convención constitucional y no necesariamente de una vez por todas: Rawls participa de la idea de que una constitución justa es algo que hay que elaborar progresivamente, e interpreta el procedimiento de enmiendas a la constitución típico de los Estados Unidos como una vía, entre otras, para ello ( $P L$, VIII, § 9; Rawls, 1998, pp. 106-112).

En lo que toca a cualquiera de estos aspectos de la diversidad social protegidos taxativamente por el Derecho, su acatamiento no hace a ninguna persona - y por supuesto a ningún cargo público— digna de ser considerada «tolerante». Y no sólo porque este acatamiento emane de una obligación legal además de moral: las libertades de conciencia y pensamiento en lo esencial - que incluirían derechos negados por una concepción no liberal de la libertad de conciencia, como el derecho al proselitismo- son valores básicos de una democracia constitucional e incluso de la cultura política democrática. Por eso de ninguna manera pueden ser objetados razonablemente en su contexto normativo. $\mathrm{Y}$ es que tales valores proscriben sin excepción cierto tipo de jerarquías entre los ciudadanos, estableciendo con ello los límites de lo tolerable. Del mismo modo por cierto que operaban los kantianos deberes estrictos de no hacer lo que rebaja a otros, derivados del respeto al hombre en general. Precisamente aquellos deberes kantianos dictan las normas de las democracias constitucionales relativas a derechos y libertades fundamentales. Las normas cuya contravención constituye un vicio «que no sólo no es un añadido moral, sino que incluso anula el valor de aquello que [como la tolerancia] en caso contrario beneficiaría al sujeto» (Kant, 1989, p. 338).

Todo esto no impide que el respeto por la diferencia obligatorio de acuerdo con los valores esenciales de la democracia constitucional y su cultura política formen parte de lo que significa llegar a ser tolerante. Es decir, no quita para que manifestar dicho respeto sea requisito previo para ser considerado tolerante. Lo cual supone que la tolerancia conlleva ciertas restricciones del juicio además del control de las consecuencias que para la conducta tendría dejarse llevar por ciertas inclinaciones (Horton, 1996, pp. 31-40). 


\section{4. 2. El espacio de la tolerancia dado por los desacuerdos razonables}

Junto al ámbito de protección taxativa e indiscutible de la diversidad social hallamos otro espacio, en el que el pluralismo emanado de los desacuerdos razonables sirve de base para distintas opciones de acción política o regulación jurídica, todas ellas razonables. En este sentido, Rawls ( $P L$, p. 228 [263]) admite que es posible definir los principios constitucionales tocantes a la estructura general del Estado y al proceso político de varias maneras. La pauta de organización funcional - $y$, cabría añadir, territorial - del poder o el alcance de la regla de la mayoría pueden ser, por tanto, razonablemente discutidos. Aunque «una vez definidos, es vital que la estructura del Estado cambie sólo cuando la experiencia muestre que lo exigen la justicia política o el bien general».

También reconoce Rawls ( $P L$, VI, § 7.1) que el empleo de la razón pública para dirimir reflexivamente una cuestión permite más de una respuesta razonable sobre ella. Tal indeterminación de la razón pública no debe despreciarse como un defecto, sino que está en consonancia con la adecuación al pluralismo razonable que corresponde a los ideales políticos de una democracia moderna. Un pluralismo que emana primordialmente de discrepancias radicadas en distintas concepciones del mundo, la historia o la sociedad con contenido normativo y consecuencias prácticas acerca de cómo debe vivirse. Distintas doctrinas comprehensivas razonables, las cuales determinan puntos de vista, también distintos y razonables, concernientes a asuntos de justicia básica. Asuntos como la legitimidad de la eutanasia, la interrupción del embarazo, el derecho a portar símbolos religiosos en la escuela, el valor académico de la enseñanza religiosa, el reconocimiento del matrimonio entre homosexuales o el significado del principio de diferencia: en cuanto a este último, una organización estrictamente meritocrática de la provisión de los cargos públicos, ¿beneficia a los menos aventajados, por su eficacia, más que el establecimiento de cuotas étnicas o sexuales?

Por otro lado, en la dudosa medida en que esto pueda distinguirse de lo anterior, el pluralismo razonable también tiene que ver con la diversidad de puntos de vista sobre cómo deben entenderse en general o en concreto los valores o principios políticos: el principio de división de poderes antes señalado ¿implica la existencia de un órgano del gobierno judicial cuyos miembros sean designados por los jueces mismos?; la salvaguardia de la integridad de un país, en determinadas circunstancias, ¿puede verse favorecida en determinadas circunstancias por un incremento del componente federalista en la distribución territorial del poder?; la defensa de la vida de los ciudadanos, y en general de la integridad del Estado de Derecho frente a una organización terrorista, ¿exige en condiciones dadas ilegalizar a un partido político 
que comparte los fines de esa organización, y algunos de cuyos miembros ha incurrido en actividades terroristas?...

Este espacio en el que el pluralismo emanado de los desacuerdos razonables sirve de base para distintas opciones de acción política o regulación jurídica, todas ellas razonables, es el propio para el despliegue de la virtud de la tolerancia. Allí donde el pluralismo es tomado como objeto de protecciones taxativas de la diversidad de convicciones y prácticas, el respeto por la libertad e igualdad de los ciudadanos se sustancia en la obligación de respetar (o hacer respetar) la integridad de ciertos ámbitos de discrecionalidad: carece de significación pública el esfuerzo moral que pueda conllevar cumplir con el deber de evitar lo inequívocamente intolerable. Sin embargo, donde el pluralismo es adoptado como fuente de opciones políticas legítimas, el respeto por la libertad e igualdad pasa por los deberes cívicos de justificar las posiciones de un modo aceptable por el conjunto de los ciudadanos, escuchar a los demás, reconocer el valor moral de sus posiciones y mostrar equidad en decidir cuándo acomodarse a sus posiciones. En estas ocasiones el ejercicio de la tolerancia, además de dar cumplimiento a una obligación ciudadana, cuenta como un mérito civil.

Y es que la cohesión de una sociedad pluralista demanda que los ciudadanos y sus representantes reconozcan que no todo aquel que mantiene convicciones distintas a las suyas es un discapacitado moral, un mal ciudadano. En este sentido, tachar de irrazonables desacuerdos que no lo son resulta intolerable. Y es obligatorio contar con la discrepancia en las deliberaciones y adopción de decisiones que no se ciñan a lo que es objeto de un pleno consenso jurídico o político-cultural. Pero, además, mostrarse tolerante respecto a otras posiciones razonables conlleva el valor añadido (supererogatorio) de estar renunciando a imponer (fáctica o contrafácticamente) disposiciones jurídicas razonables, basadas en las propias convicciones, en aras de la cooperación social.

Una posición como ésta acerca de la tolerancia que la ubica sobre todo en el campo de las relaciones políticas informales, por oposición a las relaciones institucionales básicas establecidas constitucionalmente, y que la hace radicar en la consideración libre e igual de los ciudadanos democráticos, la sostiene Scanlon (1996, pp. 230-231). Un autor con quien Rawls (1997, p. 588 [172]) reconoce una deuda intelectual en cuanto a cómo entender el fundamento de la tolerancia y a quien tácitamente sigue.

\section{4. 3. La justificación de la democracia constitucional como espacio de la tolerancia}

Con todo, el mayor espacio para la virtud de la tolerancia dentro de un régimen constitucional democrático tiene que ver con la justificación de éste. La 
justificación se realiza por referencia a una situación, real o hipotética, en la que el soporte que procuran al régimen político los procesos de socialización se torna problemático. El fundamento y la organización del poder político dejan de tomarse como dados y se convierten en una posibilidad entre otras. No contarían, por tanto, los límites de la tolerancia impuestos por las normas jurídicas que establecen protecciones taxativas de la diversidad en sus diversas formas. En el contexto de la justificación, no se entiende que los individuos hayan delegado en la autoridad de la constitución y las leyes su competencia normativa para decidir una norma que favorezca su propia cosmovisión en perjuicio de otras. Al menos, en principio.

Como bien ilustra la hipótesis de estado prepolítico de la que parte el contractualismo, cuando se trata de justificar un régimen político, el poder está en manos de cada uno de los individuos, pues el pronunciamiento de éstos es determinante para la constitución del poder. El correlato deliberativo de la referida hipótesis constituyente sería una demanda radical de argumentos susceptibles de legitimar la sociedad política, su organización y sus fines. En este contexto, según el liberalismo político, la razón de la que disponen las personas para apoyar una concepción política de la justicia que no se asienta sobre su propia doctrina comprehensiva es su compromiso con la virtud tolerancia; un compromiso debido, a su vez, a la conciencia de que es posible discrepar razonablemente sobre qué concepción del mundo es la verdadera o correcta.

Este compromiso con la virtud de la tolerancia de quienes tienen que aceptar la justificación del régimen no arranca, según Rawls, de ningún rasgo universal de la naturaleza humana. Antes bien, proviene de la participación de las personas en una cultura política uno de cuyos valores básicos es la renuncia a servirse del poder estatal para imponer las propias convicciones ${ }^{20}$. Se contempla, pues, en el liberalismo político la existencia de una entidad prepolítica integrada por normas basadas en el sentido común, de las cuales emana una autoridad no coercitiva, como la del Estado, sino voluntaria y razonable. Una entidad que sería base de la organización del gobierno y condicionante de ésta. De alguna manera, el liberalismo de Rawls incorpora la doctrina lockeana de la opinión pública. Doctrina según la cual los mismos principios y valores racionales y pertenecientes al sentido común que habían posibilitado una vida ordenada en el estado natural debían seguir guiando el orden institucional (lo que justificaba, para Locke, la forma representativa de gobierno) (Bayona, 1999, pp. 90-93). Sólo que en el liberalismo de Rawls no es un incidente la invención del dinero, lo que da al traste con el orden natural de la sociedad civil y motiva la constitución del Estado. Es buscando la publicidad de los principios compartidos y su estable reproducción en la vida civil cómo se establece una concepción política de la justicia.

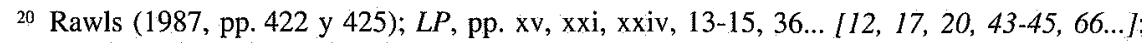
Rawls (1997, pp. 573-574 [155-56]).
} 
El reconocimiento de la existencia de desacuerdos razonables conlleva la virtud de la tolerancia, pero no sólo eso: también implica la aceptación de alguna forma de libertad de conciencia y de pensamiento y la falta de respeto de estas libertades como límite de lo tolerable ( $P L$, II, § 2.1-2, III, § 3.3-4). Con lo cual, el ámbito de la tolerancia debe entenderse recortado por lo que resulta intolerable conforme a tales ideas de la libertad. Además de esto, en la cultura política de cada sociedad concreta han podido decantarse convicciones particulares acerca de lo intolerable que amplían el espectro de esta categoría. Esto restringe, a su vez, los términos de cooperación social que pueden acordar personas divididas por desacuerdos razonables gracias a su disposición a la tolerancia.

\section{4. 4. Más sobre la tolerancia como presupuesto de la justificación de la democracia constitucional}

De modo que la justificación liberal-política del Estado justo no lleva la abstracción tan lejos como para apoyarse en la tolerancia más allá de los límites liberales de lo tolerable. Pero en cierto sentido tal justificación extiende la abstracción hasta un punto en que deja a las partes del contrato social sin convicciones que puedan ser lesionadas y por consiguiente sin nada que tolerar. Esto es así en lo que toca a las partes en la posición original, es decir, en cuanto a las personas artificiales que pueblan la hipótesis de congreso constitucional de la que se sirve Rawls para determinar la concepción de la justicia más adecuada para una sociedad moderna de ciudadanos libres e iguales.

$\mathrm{Al}$ efecto de representar tal libertad e igualdad de ciudadanía (que son las dimensiones políticas de la racionalidad y razonabilidad que caracterizan a los ciudadanos en cuanto personas morales), Rawls opera del siguiente modo: por un lado, emplaza a las partes de un supuesto congreso constituyente en una posición equitativa o simétrica, sin que ninguna posea mayores ventajas en la negociación que el resto. Por otro, las sitúa bajo restricciones de información que conducen a que la elección de la concepción de la justicia atienda a las mejores razones (lo que Rawls denomina situarlas tras el velo de ignorancia). Entre estas restricciones de información se encuentran el desconocimiento de las dotaciones innatas, la raza, el sexo, la situación social y la particular doctrina comprehensiva de las personas a quienes cada una de las partes representan. Y, plasmada la razonabilidad que se espera de los ciudadanos en el emplazamiento simétrico de las partes y en las restricciones informativas a las que se ven sometidas, la racionalidad de éstos se expresa en cómo las partes actúan: en la posición original, las partes se conducen conforme a la racionalidad estratégica y deliberativa para elegir aquellos principios de la justicia que más pueden favorecer sus intereses y 
facultades morales. Tal racionalidad desligada de todo compromiso moral concreto nada tiene que ver con la tolerancia.

Sin embargo, no hay que olvidar que la identidad de las partes en la posición original es sólo una ficción mediante la cual se representa una dimensión de la personalidad moral de los ciudadanos de una sociedad democrático-constitucional, la racionalidad, al efecto de determinar la concepción de la justicia más adecuada para una sociedad democrática. La otra dimensión de esta personalidad moral, la razonabilidad de los ciudadanos, es la que determina el emplazamiento simétrico de las partes y las restricciones informativas a las que éstas se ven sometidas. En particular, el que en una primera etapa las partes tengan vedado el conocimiento de las doctrinas religiosas, filosóficas o morales que representan obedece a la convicción de que compartir una de estas doctrinas no es razón suficiente para proponer, o para esperar que otros acepten, una concepción de la justicia que favorezca precisamente a los partidarios de ella $(P L, \mathrm{I}, \S 4.3 ; \mathrm{II}, \S 5.5)$. Y la única forma en que esta convicción puede operar en condiciones históricas, no en las hipotéticas de la posición original, es que sea experimentada por los ciudadanos como propia. Pero si esto ocurre, ante lo que nos hallamos es ante unos seres que cuentan con la virtud de la tolerancia como atributo moral y que al tiempo mantienen algún compromiso con una cosmovisión determinada. Pues, en ausencia del compromiso referido, la disposición a la tolerancia no tendría ningún valor. Esto nos sitúa ante la antes referida expectativa de tolerancia como rasgo moral de las personas para quienes se elige la concepción política de la justicia. Una expectativa que se asienta en otra: la tolerancia que deben manifestar las doctrinas comprehensivas que persisten y consiguen florecer en una sociedad constitucional democrática.

\section{BIBLIOGRAFÍA}

BAYONA AZNAR, B. (1999): «La "cultura política" en el liberalismo de Rawls», Sistema, núm. 149, pp. 69-97.

CoHEN, J. (1994): «A More Democratic Liberalism», Michigan Law Review, núm. 92, pp. 1503-1546.

De LuCAS, J. (1992): «Para dejar de hablar de la tolerancia?», Doxa, núm. 11, pp. 117-126.

- (1996): «Tolerancia y derecho. ¿Tiene sentido hablar de tolerancia como principio jurídico?», Isegoría, núm. 14, pp. 152-163.

Del Águila, R. (2003): «La tolerancia», en A. Arteta, E. García Guitián y R. MAIz (eds.), Teoría política: poder, moral, democracia, Madrid, Alianza, pp. 362-383.

DíAZ-URMENETA MuÑoz, J. B. (1994): Individuo y racionalidad moderna. Una lectura de Isaiah Berlin, Sevilla, Universidad de Sevilla.

ESCÁMEZ NAVAS, S. (2004): «La idea liberal de tolerancia en las democracias contemporáneas», Política y Cultura, núm. 21. 
FETSCHER, I. (1994): La tolerancia. Una pequeña virtud imprescindible para la Democracia. Panorama histórico y problemas actuales, v. c. de N. Machain revisada por R. Zimmerman, Barcelona, Gedisa.

GARZón VALDÉs, E. (1992): «No pongas tus sucias manos sobre Mozart. Algunas consideraciones sobre el concepto de tolerancia», Claves de Razón Práctica, núm. 19, pp. 16-123.

Gray, J. (1995): Enlightenment's Wake. Politics and culture at the close of the modern age, Londres, Routledge.

HABERMAS, J. (1998a): Facticidad y validez. Sobre el Derecho y el Estado democrático de Derecho en términos de teoría del discurso, v. c. de M. Jiménez Redondo, Barcelona, Trotta.

- (1998b): «Razonable versus verdadero, o la moral de las concepciones del mundo», en J. HABERMAS y J. RAwLS, pp. 142-181.

- (2000): «Aclaraciones a la ética del discurso», en ibid., Aclaraciones a la ética del discurso, v. c. de José Mardomingo, Madrid, Trotta, pp. 127-231.

- (2003): «De la tolerancia religiosa a los derechos culturales», Claves de Razón Práctica, núm. 129, pp. 4-12.

Habermas, J., y RAWLS, J. (1998): Debate sobre el liberalismo político, v. c. de Gerard Vilar, intr. de Fernando VALLESPÍN, Barcelona, Paidós.

HEYD, D. (ed.) (1996): Toleration: an Elusive Virtue, Princenton, Princenton University Press.

HonNETH, A. (1997): La lucha por el reconocimiento. Por una gramática moral de los conflictos sociales, v. c. de M. Ballestero, Barcelona, Crítica.

Horton, J. (1996): «Toleration as a Virtue», en D. HEYD (ed.), pp. 28-43.

KANT, I., (1975): «¿Qué es la ilustración», en Filosofia de la historia, v. c. de E. Ímaz, Fondo de Cultura Económica, México, pp. 25-39 (original de 1784).

- (1989): Metafísica de las costumbres, v. c. de A. Cortina y J. Conill, Madrid, Tecnos (original de 1797).

MCCARTHY, T. (1997): «Constructivismo y reconstructivismo kantianos: Rawls y Habermas en diálogo», v. c. de A. Valdecantos, en J. A. GimbernAT (ed.), La filosofia moral y política de Jürgen Habermas, Madrid, Biblioteca Nueva, pp. 35-64.

MARTÍNeZ DE Pisón, J. (2001): Tolerancia y derechos fundamentales en las sociedades multiculturales, Madrid, Tecnos.

MENDUS, S. (1989): Toleration and the limits of liberalism, Houndmills-Londres, Macmillan.

Nederman, C. J. (1996): «Liberty, Community, and Toleration: Freedom and Function in Medieval Political Thought», en C. J. NEDERMAN y J. C. LAURSEN (eds.) Difference and Dissent. Theories of Toleration in Medieval and Early Modern Europe, Lanham..., Rowman \& Littlefield Publishers, pp. 17-37.

Rawls, J. (1971): A Theory of Justice, Oxford, University Press (v. c. de María Dolores González, México, Fondo de Cultura Económica, 1978).

- (1980): «Kantian Constructivism in Moral Theory», en J. Rawls (1999), pp. 303-358 (v. c. de Miguel Ángel Rodilla, en La justicia como equidad. Materiales para una teoría de la justicia, Madrid, Tecnos, pp. 137-186).

- (1982): «Social Unity and Primary Goods», en J. RAwLS (1999), pp. 359-387 (v. c. de Miguel Ángel Rodilla, en La justicia como equidad. Materiales para una teoría de la justicia, op. cit., pp. 187-211). 
- (1985): «Justice as Fairness, Political not Metaphysical», en J. RawLS (1999), pp. 388-414.

- (1987): «The Idea of an Overlapping Consensus», J. RAwLS (1999), pp. 421-448.

- (1993): Political Liberalism, Nueva York, Columbia University Press (v. c. de Antoni Doménech, Barcelona, Crítica, 1996).

- (1997): «The Idea of Public Reason Revisited», en J. Rawls (1999), pp. 573-622 (v. c. de Hernando Valencia Villa, en El derecho de gentes y «una revisión de la idea de razón pública», Barcelona, Paidós, pp. 154-205).

- (1998): «Réplica a Habermas», en J. HABERMAS y J. RAwlS, pp. 75-143.

- (1999): Collected Papers, ed. de Samuel FreEMAN, Cambridge (Mass.)-Londres, Harvard University Press.

- (2002): La justicia como equidad. Una reformulación, Erin KELLY (ed.), v. c. de Andrés de Francisco, Barcelona, Paidós (original de 2001).

RAZ, J. (1990): «Facing Diversity: The Case of Epistemic Abstinence», Philosophy and Public Affairs, núm. 19, pp. 3-46.

RICHARDS, D. A. (1986): Toleration and the Constitution, Nueva York-Oxford, Oxford University Press.

- (1996): «Toleration and the Struggle against Prejudice», en D. HEYD (ed.), pp. 127-146.

SCANLON, T. M. (1996): «The Difficulty of Tolerance», en D. HEYD (ed.), pp. 226-239.

SCARMAN, L. (1987): «Toleration and the Law», en S. MENDUS y D. EDwARDS (eds.), On Toleration, Oxford, Clarendon Press, pp. 49-62.

SCHMITT, A. (1992): «Las circunstancias de la tolerancia», Doxa, núm. 11, pp. 71-85.

WALZER, M. (1998): Tratado sobre la tolerancia, v. c. de F. Álvarez, Barcelona, Paidós.

WiLLIAMS, B. (1996): «Toleration: An Impossible Virtue», en D. HeYD (ed.), pp. $18-27$. 